BELL LABORATORIES' LIBRARY

REAL-TIME LOAN SYSTEM (BELLREL)

R. A. KENNEDY: Bell Telephone Laboratories, Murray Hill, New Jersey

Bell Telephone Laboratories has established an on-line circulation system linking two terminals in each of its three largest libraries to a central computer. Objectives include improved service through computer pooling of collections, immediate reporting on publication availability or a borrower's record, automatic reserve follow-up; reduced labor; and increased management information. Loans, returns, reserves and many queries are handled in real time. Input may be keyboard only or combined with card reading, to handle all publications with borrower present or absent. BELLREL is now being used for some 1500 transactions per day.

\title{
INTRODUCTION
}

As part of a continuing program to exploit available technology to improve library service, the Technical Information Libraries system of the Bell Telephone Laboratories has established an on-line, real-time computer circulation network. The initial configuration links two terminals in each of the Holmdel, Murray Hill and Whippany, New Jersey, libraries to a central computer at Murray Hill. These are the three largest libraries in Bell Laboratories, handling $75 \%$ of a system total of more than 300,000 loans per year. The BELLREL system is designed to process loans, returns, reservations and queries with real-time speed and responsiveness; additionally, it provides a wide range of other products and information basic to the effective control and use of library resources.

The libraries of Bell Laboratories, like many other research libraries, have experienced unprecedented growth over the past decade in facilities, collections, services and traffic. New approaches have had to be found 
not only to supply information services of sufficient power and diversity to meet the needs of a communications research organization of over 15,000 people, but also to cope with the expanding volume of everyday work in its eighteen library units. As elsewhere, a large component of that work is circulation in all of its ramifications: direct service, record-keeping, follow-up, resource identification, inter-unit coordination, feedback for purchase and purge decisions, etc. The BELLREL system is addressed to these problems within the context of the Bell Laboratories.

The use of computers in circulation control is no longer novel. The studies done by George Fry and Associates for the Library Technology Project of the American Library Association emphasize the expense of implementing computer-aided circulation systems (1,2). Despite these studies, which tend to focus more on the gross costs of substituting data processing for manual techniques than on the immediate and long-range gains for the library as an information system, a trend to the computer is clear. Southern Illinois (3), Lehigh (4), and Oakland (5) are among the many university and research libraries which have automated circulation operations using the IBM 357 Data Collection System and batch processing. Comparable systems are in use or planned by other libraries $(6,7)$. Latterly there is increasing evidence of serious interest in real-time circulation control. The Queen's University of Belfast (8), and the State University of New York at Buffalo (9) are two institutions reporting studies. Redstone Arsenal has been demonstrating a two-terminal, on-line system for about a year as part of a comprehensive automation program (10).

The BELLREL system was put into regular service in March, 1968, after two months of dry-run testing at all six terminals. This paper describes the reasons for changing from a manual system; the objectives established for the new system; the alternatives evaluated; the principal elements, operations and services of the selected system; and problems and performance in the brief period of operations to date. The paper is essentially a summary description; it does not report in detail on all card, disk and tape formats, maintenance procedures, products, logical operations, etc., of the system and its fifty-plus programs. A further report on BELLREL will be published when significant experience has accrued.

\section{THE DISPLACED MANUAL SYSTEM}

The Newark self-charge-signature system has been used by Bell Laboratories' libraries for some forty years. In this well-known simple system, the borrower writes his name and address on a prepared book card pulled from the book pocket. For the two out of three loans at Bell Labs where the borrower is not present, a circulation assistant fills out the card, which is then date stamped, tabbed for date due and filed by author. Minor variations on this practice are used for unbound journals and other items lacking book cards. 
Reservations for individuals or other libraries in the network are hand posted on the charge card. Files are scrutinized for overdue dates every several days (latterly, less frequently as traffic has mounted) and notices prepared by Xerox copying of the charge card on an appropriate form. Although standard loan periods run from one to four weeks, depending upon the item and demand, about $30 \%$ of all loans result in overdue notices.

Each library in the network has maintained its own circulation records, including records for the local circulation of items borrowed on interunit loan. Inter-unit traffic is heavy, although substantial duplication of important publications exists in the various libraries.

The merits of the Newark self-charge system-simplicity, fast handling of borrowers, relatively low cost-are widely known. The system is a venerable one; it works. But all circulation systems have imperfections and in the Bell Laboratories long-recognized deficiencies of the manual system became increasingly unacceptable when loan traffic began to approach, then exceed, 200,000 items per year.

These deficiencies included:

1. An increasing number of hours spent on the tedious and uninspiring tasks of sorting, tagging, posting, slipping, checking and husbanding cards.

2. Labor, frequent delays and poor service associated with processing over 60,000 overdue notices per year.

3. Inability automatically to use the pooled resources of several libraries to meet demands.

4. Inability to determine quickly not merely the holdings of other copies of a title in the library system (union catalogs serve this purpose, after some steps and card handling) but the availability of loan copies at the moment of need.

5. Inefficiencies in tracking down missing publications, inventory items, etc.

6. Inability to identify all publications currently on loan to a borrower or used by him sometime previously.

7. Inadequate information on collection use for resource management.

8. Excessive service delays due to combinations of the preceding factors.

\section{NEW SYSTEM OBJECTIVES}

The deficiencies listed above suggest some of the characteristics defined for the new system. Library management concluded early in 1965 that any replacement for the existing system must:

1. Meet the long-range needs of each of the major libraries in Bell Laboratories and be extensible to other units in the library network as traffic, experience and costs warranted.

2. Provide not merely a more effective means for handling circulation operations within the walls of any one library but also, if possible, 
an instrument for knocking walls down, for bringing the combined resources of a number of libraries to bear on any information need.

3. Handle all types of materials, bound or unbound, and all types of requests whether in person, by mail, direct telephone or recorded message (i.e., Telereference) service.

4. Give immediate up-to-the-minute accounting for all items on loan or otherwise off the shelves and locate copies still available for loan.

5. Hold reservations against system resources (in line with objective 2) and direct the first copy returned, wherever returned, and as automatically as practical, to the first person on the reserve queue, whatever his base location.

6. Identify promptly all items currently charged to a borrower and, as required, previously borrowed by him.

7. Monitor circulation traffic and generate, as necessary, overdue notices, missing item lists, high-demand lists, zero-activity reports, statistics, use analyses and other feedback fundamental to effective control and management of the collection.

8. Lift the circulation staff from clerical tasks to more personal service to library users, in the interest of the "human use of human beings," to use Norbert Wiener's phrase.

9. Integrate the loan system with other computer-aided systems in use or planned in the libraries.

10. Improve the total response of the library to the user.

\section{SYSTEMS EVALUATED}

In view of these objectives it will be apparent that only a computeraided system could be seriously considered. None of the several dozen noncomputer systems surveyed in the Fry report (1) could be considered a worthwhile alternative to the Libraries' manual system.

The essential questions therefore became: Off-line or on-line access? Batch or real-time processing?

The demonstrated success of the IBM 357 batch processing circulation system compelled study and on-site investigation in several libraries. It was concluded, however, that while the 357 system would meet a number of the established goals, and at moderate cost, the important objectives of immediate accountability, automatic follow-up on reserves, full disclosure of copies available for loan, and automatic pooling of network resources would be seriously compromised. Further, the fact that twothirds of all loans made in Bell Laboratories do not involve the presence of the borrower substantially detracted from one of the major virtues of the 357 system, i.e., the simplicity of input using a pre-punched man (identification) card submitted by the borrower. The various alternatives for coping with this situation in a 357 system, for 200,000 loans a year and a potential of over 15,000 people, were not attractive. 
The feasibility of on-line access has been widely demonstrated in the research and business world. Remote, on-line computer processing is clearly a common course of the near future. Equally predictably, it will steadily give more favorable cost/value ratios as machine costs decrease and labor costs mount. In sum, the Technical Information Libraries concluded that an on-line system was worth the investment and that no other system was worth the price. Only an on-line approach would meet the overall objectives for a new system and offer advantages sufficient to justify conversion effort at this time. As Frederick Ruecking has observed, "A charging system should not be selected because it is 'cheaper' than others. If the selected system does not meet the present and future needs, the choice is poor." (11)

\section{THE BELLREL SYSTEM}

BELLREL is a joint development of the Technical Information Libraries and the Comptroller's Division of Bell Laboratories. The system was designed, programmed and implemented in a little over two years, beginning in late 1965. During this time, preparation of the bibliographic records, system design and programming took about seven man years.

\section{Basic Machine Elements}

The initial network is illustrated in Figure 1. The two IBM 1050 ter-

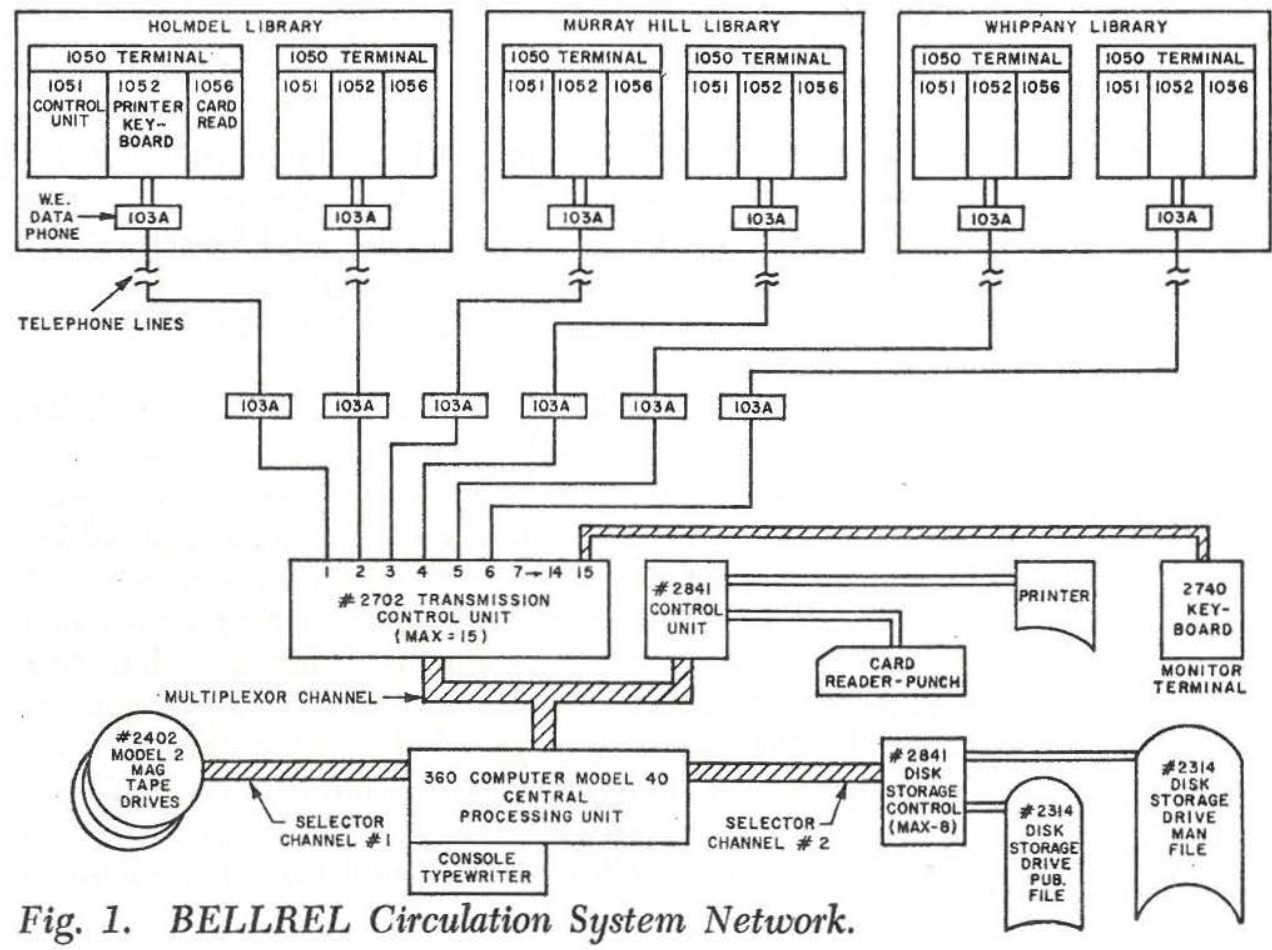


minals in each of the three libraries incorporate keyboard, printer and card reader facilities for maximum flexibility in handling all types of transactions and queries. Each terminal is linked by telephone lines, using Western Electric 103A Data-Sets, to an IBM 360-40 computer in the Comptroller's Division at Murray Hill. The Murray Hill Library is only a building away from the computer. The Holmdel and Whippany Libraries are about thirty and twelve miles distant, respectively.

The computer, in heavy daily use along with other computers for regular operations of the Comptroller's Division, has a 262,000 byte (character) core memory. Core is partitioned, permitting effective simultaneous use of the computer for routine batch operations and the BELLREL system. In addition to core requirements for the 360 Operating System, core partitions include (a) the teleprocessing logic of the IBM Queued Teleprocessing Access Method (QTAM), (b) message editing logic and application logic packages, including library applications and (c) batch processing programs and operations for all purposes. Figure 2, a flowchart of the real-time processing logic, illustrates core partitioning for

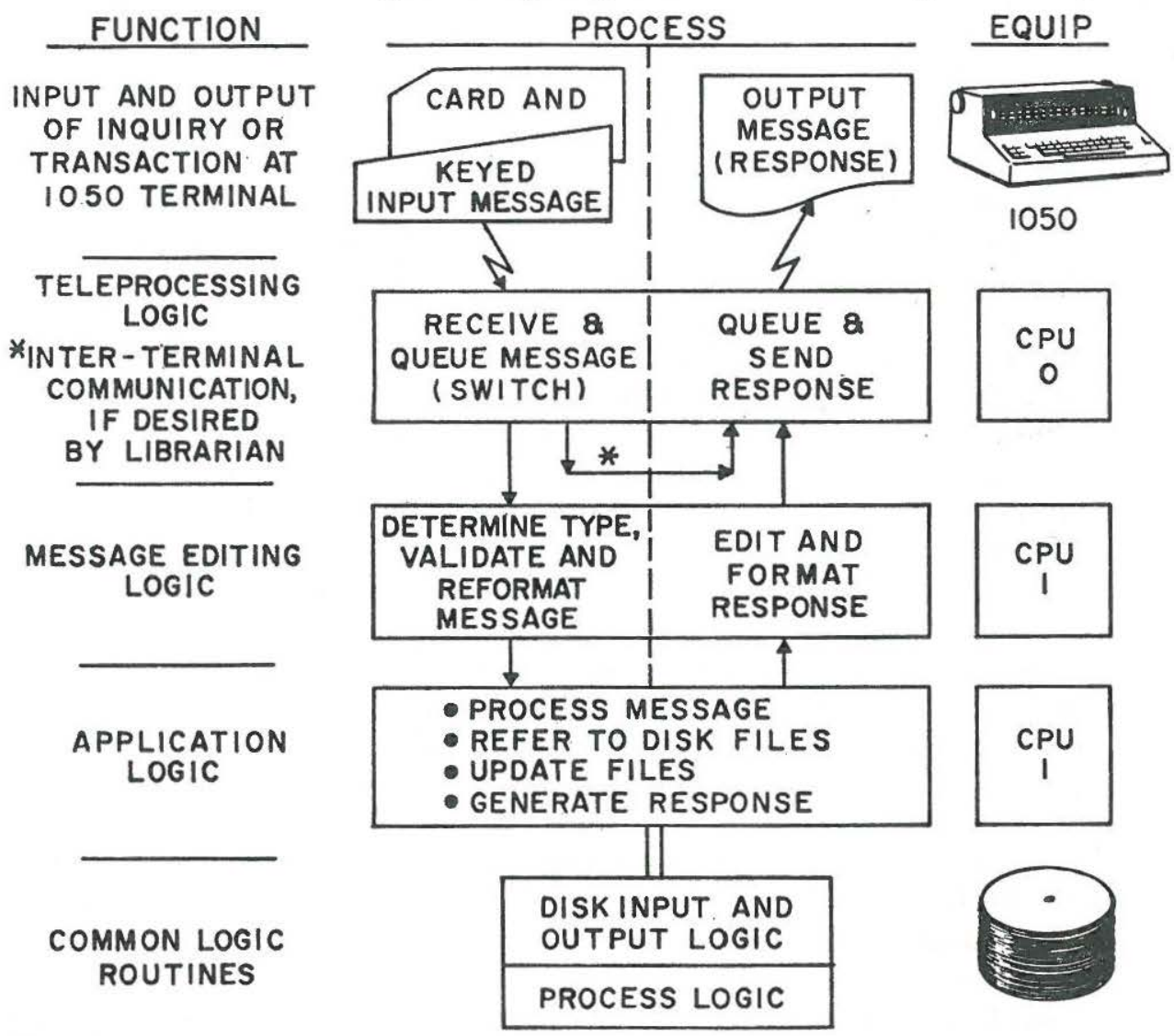

Fig. 2. General Flowchart of BELLREL Real-Time Programming Logic. 
(a) and (b). In addition to the programs resident in core (portions of which can be overlaid as necessary by other real-time operations) certain programs for particular functions (e.g. loan, return, etc.) are called from disk as needed. In all, 32 real-time and 23 batch programs, together with the 360 Operating System, are used by BELLREL. The programs are written in COBOL level $\mathrm{F}$ and Basic Assembly Language.

\section{Disk Records}

Publication and man records are stored on an IBM 2314 disk pack with a capacity of some $29,000,000$ characters. About two-thirds of this space is in use or dedicated. The man records, which are up-dated daily from tape used for telephone directory, payroll and other purposes, cover about 19,000 people including BTL employees and Resident Visitors, i.e., contractual people who may also use library facilities. Each man record is 161 characters in length and contains such information as payroll account number, name, department number, telephone number, location, occupational class, space for three book loans, keys referring to overflow loan trailers elsewhere on disk, etc. The man file is organized by payroll account number, a five-digit number which is keyed in or read from a prepunched card for all loans, reservations and other transactions requiring it. Access to man records on disk is by the IBM Index Sequential Access Method (ISAM).

Publication records vary in format, length and method of access depending upon the class of publication. Five classes of publications are currently in the system: books (Class 1 ), journals (Class 2), trade catalogs (Class 3), college catalogs (Class 4) and Dewey-classified continuations and multiple-volume titles cataloged as sets (Class 5). Other classes of information, e.g., documents, motion picture films, etc. will be added. Each title in each class is assigned a unique six-digit identification number, the first digit of which identifies the class. A typical number for a monograph title is 127391 . The punched cards and book labels for each copy of this title also indicate the holding library and its copy number, e.g., 127391MH01, 127391WH05. A sample card and label, generated by the computer, are shown in Figure 3.

As noted above, books fall in two classes-1 and 5. Each class provides a maximum of 100,000 title numbers, more than adequate for the predicted growth of the Technical Information Libraries where weeding is heavy. The book collections for the three libraries now on disk total about 33,000 titles and 66,000 volumes.

The disk record for each Class 1 title is 188 characters in length and contains the book number, 43 characters of author-title, the call number, copies by location, the fields for file maintenance change information, three loans, two reserves, keys to loan trailers and reserve trailers, etc. Each loan field identifies borrower, date due, copy and status of the loan (e.g., overdue number, renewed, number of reserves, returned). The 


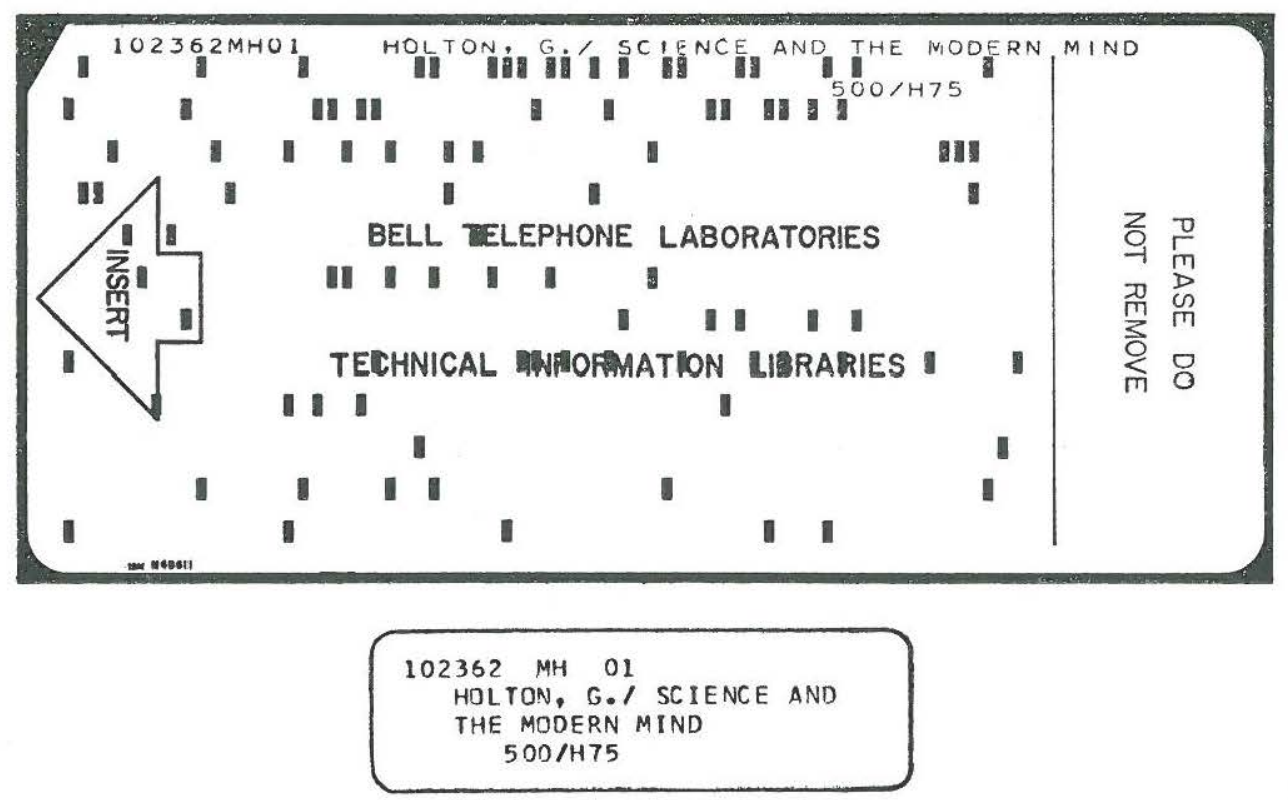

Fig. 3. BELLREL Book Card and Label.

identification number for each new Class 1 book is assigned by the computer on update runs. Numbers are sequential. Disk access is direct.

Class 5 books-cataloged continuations and multiple-volume titles cataloged as sets-share a different kind of disk record. They could all have been entered as Class 1 items, in which case each volume of a set would have had a separate record on disk, a unique (not necessarily consecutive) identification number, and a separate listing in the author, call number and identification number printed catalogs. The Class 5 approach, however, permits grouping of volumes in sets and series. Ten volumes of one title are handled in one disk record, 288 characters in length, under the same identification number. Additional volumes, up to a total of 100 , are handled in succeeding records. All of the records of the set carry the same first five digits in their identification number. Disk access is by the Index Sequential Access Method (ISAM). In addition to grouping sets, Class 5 records effect a saving on disk space and permit use statistics to be derived for the set as a whole, as well as for each volume in the set. The principal disadvantage of the approach is that all keyed messages dealing with any volume in the set must cite both the basic access number and the specific data (e.g., volume number) pertinent to the volume in question.

The journal disk records cover all the 2700 journal titles held in the library system. Unlike books, however, records of all copies and volumes of each title are not permanently stored on disk. Instead, each 155character journal title record contains the journal identification number 
and 48 characters of title, plus fields for file maintenance changes, two loans, one reserve, and keys to loan and reserve trailers. Specific bound volumes or unbound issues are recorded on this record only as long as they are current loan or reserve transactions. To expedite loans and returns, punch cards and computer-printed labels have been prepared for some 10,000 bound journal volumes. Additional volumes are similarly processed as circulated or bound.

Disk records for trade catalogs and college catalogs are also 155 characters long. Access to records is also by the Index Sequential Access Method. Unlike journal volumes, however, each separate catalog is specifically identified and recorded on disk. When conversion is complete, more than 5000 catalogs will be accessible on disk.

The loan and reserve trailers for each publication class accommodate overflow. Trailer records vary in number and length depending upon function, publication type and predicted need. For example, 5000 31character trailer records, each handling three reserves, are available for book reserves. For journals, 800 59-character records, each handling three reserves, are provided. The difference reflects the heavier book traffic and the particularly sharp peaking of reserves on new book titles.

Apart from the normal safety back-up files (e.g., the nightly dump to tape of the current disk records), the only remaining machine record which requires mention is the history tape. This tape, up-dated daily, is a continuing record of all completed loans which provides information necessary for statistics and use analyses.

\section{On-Line Transactions}

Twenty-two different transaction codes are currently available to handle loans, returns, renewals, reservations and queries in real time. In addition, any terminal can call another terminal by a single digit code and one terminal in each library can call the other two libraries simultaneously by a 'broadcast' code. This inter-library, typewritten message facility is a highly useful component of the total system.

Ten of the twenty-two transaction codes handle loans, returns, reservations and renewals. These codes, their prime functions and associated data inputs are listed in Table 1. The eleven LQ (Library Query) codes for requesting information from BELLREL are listed in Table 2. One additional code causes the computer to print out at the query terminal a statistical log of all classes of transactions at each terminal and their totals. It also gives the number of input errors made at each terminal. The log aids in adjusting work loads and monitoring performance.

Let us now consider several common transactions in more detail.

\section{Loans:}

If the borrower is present, he gives the desired book to the circulation clerk. He shows his badge or, alternatively, writes his surname and five- 
Table 1. On-Line Codes for Loans, Etc.

Code

1. Loans

LM

LN

2. Returns

LC

LK

3. Reserves

LA

LB

LD

4. Renewals, etc.

LP

LR

LG
Function

Loan of 1-5 items for one man at one time.

Overnight loan. Assigns overnight loan period automatically; does not pick-up reserves on return.

Cancel loan. Charge out automatically to first person on reserve queue.

Cancel loan. No automatic charge-out.

Add to reserve queue. Give reserve no., copies held and available, etc.

Bypass reserve queue. Put designated man first.

Delete from reserve queue.

Change loan period assigned.

Renew loan, once.

Force renewal irrespective of reserves, overdue status, etc.

\section{Input Data \& Method}

Man no., item no. (including location and copy). Usually card read.

Item no., with location and copy.

Usually card read.

Man no., item no. (less location and copy). Keyed.

"

New loan period, complete item no. Keyed or card read.

" 
similar messages are not accepted by the system. Recovery from errors may be done by aborting input, repeating it correctly or, if all elements are legitimate to the message edit program, by using the appropriate online code to correct the record.

On the first day of full operations, $10 \%$ of the input transactions were incorrect. One week's experience reduced the error rate to $3 \%$, and further improvement is expected. The $.25 \%$ error rate estimated by Lazorick and Herling for a system planned to function without any prepunched cards (9) appears unrealistic.

\section{Non-Personal Codes}

Some thirty special codes, which function like man numbers in the system, are available to handle real-time transactions involving branch libraries, outside organizations and such internal library functions as charges to recataloging, repair, new book shelf, etc. All are three-digit codes, essentially mnemonic, e.g., AL9 - Allentown (Pa.) Library; WI9Withdrawn. Most of the codes generate overdue notices; the codes for binding, missing, repair and a few others do not. Several require backup manual records, e.g., ALA interlibrary loan forms for charges to outside libraries.

\section{Batch Processes and Products}

Overdue notices and daily loan lists are produced in a nightly file maintenance run which also updates the history tape. The preprinted forms used for first and second overdue notices are address-sorted for direct mailing. The third notice, triggered three days after the second and ten days after the first, is a listing with telephone numbers and other data for telephone follow-up.

The daily loan list is primarily a back-up record in the event of system down-time. Current loans, the number of reserves and other information are combined in one list for all three libraries.

The BELLREL master book catalog is run quarterly from disk records. Main entry, Dewey number and access number catalogs are produced. All new copy, new title and other record changes made on disk in maintenance runs are reflected in cumulative weekly catalog supplements. These runs also produce all the new or changed cards and labels required.

The BELLREL catalog is a precursor to a system-wide printed book catalog which will replace nearly one million catalog cards held in eighteen libraries. When completely developed, input to the circulation system will be a sub-system of the master catalog maintenance procedures. Maintenance of the disk journal records for BELLREL follows a comparable integrated approach: journal code numbers, title abbreviations, data changes and the like are derived from the computer routines used to prepare the serials catalog since 1962. Trade catalog files for the 
the book and the number of copies still available for loan at each library. Getting one copy into the hands of the requester is then very simple. The holding library nearest to the borrower is instructed, by telephone or terminal message, to send call number such-and-such "out." The requester's name and address are not relayed. The holding library gets the book from the shelves and cancels it, using the LC command with the card reader. Although this copy was not on loan, the computer ignores this fact because someone is waiting for the book, i.e., the requester whose reserve triggered this sequence. As a consequence of the cancel operation, the requester is automatically charged with the book, the holding library is told his name and address, and mailing follows. The LC command is also used in the same way to get additional copies of a book, when purchased to meet high demands, into the hands of the requesters.

The LA reserve transaction is put to particularly good use in handling the 600-plus requests received within a few days each month for new books announced in the Library Bulletin. Bulletin Request Forms supply both item numbers and man numbers. Mass input follows and the computer responds with all the signposts needed to put every copy in the system to work, with a dispatch speed hitherto impossible to achieve.

As shown in Table 1, two transactions permit changes in reserve queues. $\mathrm{LD}$ deletes a requester. $\mathrm{LB}$ permits the queue to be bypassed and insertion of a new name at the top of the list.

\section{Queries}

This is a fact retrieval facility. The codes listed in Table 2 are reasonably self-explanatory, and take into account the realities of on-line circulation service. LQC, for example, tells the status of a title at the moment of asking, an up-to-dateness not available from the backup daily loan list generated each night. Typical responses to the LQC code are: COPIES AVAILABLE, MH02 WH01; TITLE REMOVED MY68; or ALL 03 COPIES LOANED, 14 RESERVES

Similarly, LQL provides a requester with an immediate, printed listing of all the items he has on loan. Two query codes cause display of the complete disk record for a publication (LQD) or a person (LQE), including current loans, reserves and trailer records.

\section{Error Detection}

In any keyboard operation mistakes will be made. BELLREL attempts to signal critical errors and prevent them from affecting records. As noted previously, input man numbers and item numbers are translated by the computer into alpha characters. Numerous diagnostics are also returned: e.g., INVALID TRANSACTION CODE; INVALID BOOK ID \#; INVALID EMPL \#; INVALID TRANSACTION BAD COPY \#; VARIABLE DATA REQUIRED, etc. Incorrect inputs generating these and 
Table 2. On-Line Library Query Codes.

\section{Code \\ Query}

1. Publications

LQC

LQS

LQN

LQD

2. People

LQM

LQL

LQQ

LQR

LQW

LQZ

LQE

Who is man number ....?
What is the status of title ...?

What is the status of copy ...?

What overnight items are still out?

Display the complete disk record for title ....

How many items are on loan to ... ?

What items are charged to ....?

Who is first on the reserve queue for ....? Is man . . . on reserve? Where?

Who are the borrowers of title...?

Display the complete disk record for man ....
Input Data \& Method (All queries are keyed.)

Item no. (less location and copy). Item no. (with location and copy). Location symbol only.

Item no. (less location and copy).

Man no.

Man no., item no. (less location, copy).

Man no. 
digit number on a card. While he is doing this, the clerk hits the 'Request' button on the keyboard-printer, and inserts the book card in the card reader along with an End-of-Transmission card. With the keyboard 'Proceed' light on ( 2 seconds after 'Request'), the clerk returns the typewriter carriage and keys in LM (the loan code) and the man number obtained from the borrower: e.g., LM43486. Input is completed by activating the card reader. The card reader reads only to the End-of-Block punch (column 16 in book cards), ignoring the author-title data and call number in columns 17-78. As the book identification number is read, it is listed on the typewriter.

The loan period is not punched in the card, but is assigned by the computer on the basis of the first digit of the publication's identification number. The assigned loan may be altered from the keyboard, if desired.

The computer responds to the loan transaction in 3 to 5 seconds, printing back in upper-case red the first three letters (trigram) of the borrower's surname and twenty characters of the book's author-title entry. These responses provide checks against errors in keying. Man numbers are usually keyed (although they may also be card read) and a book number is keyed when its punch card is not available, e.g., in posting a reserve. As noted below, a wide range of other computer responses are available to flag errors and aid diagnosis.

The loan transaction is completed by inserting the punch card in the book and date stamping it. Total elapsed time from the borrower's presentation of the book to date stamping averages about 23 seconds for a single loan of the type described. This compares with about 20 seconds cited for one IBM 357 system (3) and 14 seconds in Bell Laboratories manual system; however, in both these systems further processing is required. If a borrower wishes to charge out more than one book at a time (a common occurrence which ruled out punching the End-of-Transmission code on the book card), up to five books may be handled with one keyboarding. Total elapsed time for multiple loans averages about 15 seconds per book.

Loans of bound journals, trade catalogs and other publications with prepunched cards follow the routine described. For unbound journals and other items lacking cards, it is necessary to obtain the title number from the printed catalog and to key this in with the relevant issue information.

Other transaction codes, as noted in Table 1, deal with loan period changes and renewals. Typical computer responses from the renew code (LR) include: RENEW; OVERDUE; RES WAITING; NO RENEW.

\section{Returns}

The two-character return code (LC) is used with card reading or typing. Five items may be discharged with one LC action. The computer 
responds with twenty characters of author-title, and one of the following messages, for each item:

RETURNED

LOAN TO . .

the loan period shown.

MAIL TO ... LIBR i.e., this book belongs to the library shown and should be returned there. No one is waiting for it.

NOT ON LOAN i.e., this book was previously cancelled or somebody 'borrowed' it without charging it out.

The LOAN TO . . . response noted above is a particularly valuable service and time-saving feature. In effect, if any reserve exists anywhere in the system for the title, then the first copy returned is automatically charged to the first person in the queue and the next person moved up. The loan period assigned by the computer depends upon whether there is a waiting list for the book. The library does not need to take any charge-out action except to date stamp the book and address a mail envelope using the information provided.

The MAIL TO ... LIBR response, calling attention to the fact that the book should be returned to its 'home' library, is coupled with automatic charging by the computer to IN TRANSIT TO . . . Questions about the copy will receive this response during the time it takes to ship it to its home base. When the book is cancelled at the home library, any reservations made during the 'in transit' phase will cause automatic loan in the manner already described.

Cancellation of a loan charge without automatic follow-up on the reserve queue is sometimes desirable. For example, after a copy of a book has been charged to 'MISSING' and search has failed to locate it, a charge to 'LOST' may be desirable for record purposes. Use of the LK return code, instead of the normal LC, makes this possible without automatic pick-up of the reserve queue.

\section{Reservations}

Since reserves are posted in BELLREL in real time, any copy of a title returned, even seconds after the reserve is made, will be charged to the first man on reserve. Reserves are input using the keyboard sequence LA Man Number, Item Number. The computer response includes the standard name trigram and publication data. If all copies of the title are on loan, the computer also responds with information to the requester on where he stands; as an example, "RES \#03, COPIES HELD $05^{\prime \prime}$.

If all copies are not on loan, the response includes the call number of 
circulation system are similarly correlated with other existing machine processes and products.

As stated earlier, much improved feedback on collection use, demand patterns, and other matters important to library management was a major goal of BELLREL. The history tapes serve this purpose both for special-purpose analyses and regular system reports. The latter include circulation statistics by subject class and library, laboratory location, user department and so on. Three other reports may be mentioned:

1. High-Demand List-This is a weekly list focusing attention on all titles with more than a specified number of reserves. Reserves and copies are shown by location. Previous loan totals are also given to aid in purchase decisions to meet demands.

2. Zero-Loan List-This is a semiannual listing of all titles in the collection with no recorded loan activity in one or more libraries for the period surveyed. A summary of previous loans is given, to help in decisions on weeding.

3. Missing Items List-This is a twice-monthly, Dewey-ordered list of all titles charged to 'MISSING.' It is used to conduct scheduled searches in all libraries until the items are converted to 'LOST' and replaced or withdrawn.

\section{OPERATING EXPERIENCE}

This paper is being written after only one month's use of BELLREL in regular service. The following observations are therefore limited.

Circulation Assistants have adapted very quickly to the input mechanics, familiarity with typewriter keyboards and the novelty of conversing with the computer being contributing factors. BELLREL appears to be regarded as a powerful and perceptive colleague with the occasional off moments accepted in a friend.

Burdensome tasks, such as preparing overdue notices and maintaining card records have been dropped with enthusiasm. Staff members are developing new perspectives as they understand the functioning of an information network. The total system concept, embracing the resources of all participating libraries and permitting one copy of a book to serve many readers without inter-library loan, is modifying many practices.

Greater record accuracy, completeness and utility is also being realized, along with significant time-savings throughout the system.

The query facility, which shows promise of being much used, provides immediate answers to certain questions which previously could not be asked and gives a glimpse of the eventual responsiveness of a complete on-line library catalog.

Customer reaction has ranged from some technical interest (technical staff members were consulted in the development of the system and information about its purposes and functions has been widely disseminated) to more common approval and enthusiasm. The increase in time to charge 
out a book in person in BELLREL-about nine seconds more than the manual system for a single loan and two seconds more per book for multiple loans-appears to be widely accepted. Whether this is due to initial tolerance of a new system, or less 'work' by the borrower in the charge operation, or an appreciation that service as a whole will be faster and more responsive, is not known. It is expected that charging time will be reduced with program modifications and experience. It should also be recalled that in two out of three loans the borrower is not present: far from experiencing additional delay, he gets what he wants faster.

The usual bugs in a complex of programs have arisen; certain trailers had to be enlarged; the 360 Operating System and hardware have failed several times. Down-time, under initial loads of up to 1500 on-line transactions per day, has been less than anticipated for the first month and is expected to drop sharply. About two down-times per day were experienced in the first month, about half of these being deliberate, and most recoveries have taken less than fifteen minutes. Down-time logs are used to record transactions for immediate entry into the system when it becomes alive, a similar procedure being used for after-hours loans.

\section{COSTS}

The costs of operating the BELLREL system are, understandably, higher than the displaced manual system, the two systems, of course, not being comparable in services and functions. In the operations which can be fairly directly correlated, BELLREL permits very significant labor savings. Appreciable materials savings are also anticipated as a result of collection pooling (leading to reduced duplication of resources in the individual libraries), better inventory control, and other factors.

Rental costs are the major component. Each of the six terminals, for example, with associated Data-Sets and telephone lines, costs $\$ 275$ a month. Costs of the portion of the transmission control unit and disk facility used by the libraries total about $\$ 1100$ a month. In addition to a small amount for materials, other costs include a share of the central processing unit and core memory charges, depending upon usage. To execute 1500 real-time transactions per day appears to require less than 12 minutes of main-frame computer time, but a share of the real-time terminal polling and batch processing time must also be included. However, experience with the automated system has been far too brief to reach any precise cost figures for the whole system. In particular, although the dollar value of the largely intangible but very real benefits to library users and library staff can only, at least at this stage, be guessed at, BELLREL has been implemented on the premise that these benefits are major.

It should be noted that the costs of the manual (Newark) system in Bell Laboratories differ greatly from the costs calculated by the Library Technology Project (LTP) for this system in an academic library (12). 
LTP cost estimates for both the Newark and the IBM 357 systems do not conform to our calculations for more reasons than can be discussed here. In the main, however, environmental conditions, strongly affecting labor costs, are too different. For example, in arriving at labor costs, LTP uses the figure of 44 overdues per 1000 circulations in academic libraries; in our library system where there are no fines or long loans, overdues total about eight times this figure. Again, as a result of book announcement services, discipline concentration and other factors, reserves in the Bell Laboratories libraries are nearly twenty times the ratio used by the Library Technology Project for academic libraries. Still further, in Bell Laboratories some 200,000 loans per year are made without the borrower being present to fill in the loan card. These and other factors add heavily to the cost of labor. Few industrial organizations can obtain labor at the cost of $\$ 2.00$ per hour cited in Library Technology Reports when personnel benefits and other overhead are included.

\section{CONCLUSION}

Paul Fasana has observed: "Since cost is primarily a quantitative measure of a system, it is but one of several factors (and possibly not even the most important factor) to consider in evaluating an automated system. Other factors ... . qualitative factors . . . must also be considered. ... . They include such items as operating efficiency, reliability, services rendered, and growth potential." (13)

A full judgment on these factors in the BELLREL system must await further experience but the following observations may be made: 1) BELLREL is not an experiment; it is addressed to practical problems in an industrial library network. 2) It is not a final system; software and hardware evolution will see to that. 3) It is not a model system, transportable in toto to another context; any system of comparable complexity and investment requires careful matching to local needs and objectives.

BELLREL objectives, to reiterate, include improved service through computer pooling of dispersed library collections, up-to-date reporting on the status of any publication, immediate identification of all items on loan to a person and automatic follow-up on reserve queues; reduced clerical labor; better inventory control; much enriched feedback for library management; more effective realization of the information network philosophy; and experience in the new era of man-machine communication in a real-life environment. The evidence is strong that these objectives are being achieved.

\section{ACKNOWLEDGMENTS}

The Technical Information Libraries gratefully acknowledge the unstinting and imaginative aid given by the Comptroller's Division of Bell Tel- 
ephone Laboratories in the design, development and operation of the BELLREL system.

\section{BIBLIOGRAPHY}

1. George Fry and Associates, Inc.: Study of Circulation Control Systems (Chicago: ALA, 1961).

2. American Library Association, Library Technology Project: The Use of Data-Processing Equipment in Circulation Control (Chicago: ALA, July 1965), Library Technology Reports.

3. McCoy, Ralph E.: "Computerized Circulation Work: A Case Study of the 357 Data Collection System," Library Resources \& Technical Services, 9 (Winter 1965), 59-65.

4. Flannery, Anne; Mack, James D.: Mechanized Circulation System, Lehigh University Library (Center for the Information Sciences, Lehigh Univ.: Nov. 1966), Library Systems Analyses Report No. 4.

5. Cammack, Floyd; Mann, Donald: "Institutional Implications of an Automated Circulation Study," College \& Research Libraries, 28 (March 1967), 129-32.

6. Cuadra, Carlos A., ed.: American Documentation Institute Annual Review of Information Science and Technology, Vol. 1. (New York: Interscience, 1966), pp. 201-4.

7. McCune, Lois C.; Salmon, Stephen R.: "Bibliography of Library Automation," ALA Bulletin, 61 (June 1967), 674-94.

8. Kimber, Richard T.: "Studies at the Queen's University of Belfast on Real-Time Computer Control of Book Circulation," Journal of Documentation, 22 (June 1966), 116-22.

9. Lazorick, Gerald J.; Herling, John P.: "A Real Time Library Circulation System without Pre-Punched Cards," Proceedings of the American Documentation Institute, v. 4 (Washington: ADI, 1967), 202-6.

10. Croxton, F. E.: On-Line Computer Applications in a Technical Library (Redstone Scientific Information Center, Redstone Arsenal, Alabama: November 1967), RSIC-723.

11. Ruecking, Frederick, Jr.: "Selecting a Circulation-Control System: A Mathematical Approach," College \& Research Libraries, 25 (Sept. 1964), 385-90.

12. American Library Association, Library Technology Project: Three Systems of Circulation Control (Chicago: ALA, May 1967), Library Technology Reports.

13. Fasana, Paul J.: "Determining the Cost of Library Automation," ALA Bulletin, 61 (June 1967) 661. 